\title{
PERHITUNGAN JUMLAH BAKTERI PADA ANGGUR LAUT (Caulerpa sp ) YANG DIPERJUAL BELIKAN DI SEPANJANG PANTAI TAKALAR
}

\author{
Anita $^{1)}$, Dewi Arisanti ${ }^{1)}$, Syamsuddin ${ }^{1)}$ \\ 1) Politeknik Kesehatan Muhammadiyah Makassar \\ Alamat Korespondensi: anitadinar1983@gmail.com
}

\begin{abstract}
Abstrak
Anggur laut (Caulerpa sp) adalah golongan alga hijau, thallus (cabang) berbentuk lembaran, batangan dan bulatan, berstruktur lembut sampai keras dan siphonous. Faktor-faktor yang mempengaruhi cemaran bakteri pada anggur laut yaitu pencemaran melalui udara, air, alat-alat pengolahan, proses pengolahan dan penyimpanan. Tujuan penelitian ini adalah untuk mengetahui berapa jumlah bakteri yang terdapat pada anggur laut (Caulerpa sp). Penelitian ini bersifat obserfasi laboratorik yang bertujuan untuk menhitung jumlah bakteri pada anggur laut (Caulerpa sp). Sampel yang diteliti adalah 10 sampel dengan metode yang digunakan dalam penelitian ini yaitu Angka lempeng total (ALT). Hasil penelitian diperoleh 9 sampel yang memenuhi syarat untuk dihitung (30-300) koloni yang tumbuh yaitu sampel 1, 2, 3, 4, 5, 6, 7, 8, dan 9. Sedangkan untuk sampel 10 koloni yang tumbuh tidak memenuhi syarat untuk dihitung (<30). Dari hasil penelitian dapat disimpulkan bahwa dari 10 sampel anggur laut (Caulerpa sp) yang telah diteliti didapatkan hasil yang sesuai ketentuan SNI 7388:2009 dan masih termasuk dibawah standar yang telah ditentukan sehingga anggur laut (Caulerpa sp) yang diperjualbelikan di sepanjang pantai Takalar masih layak untuk dikonsumsi.
\end{abstract}

Kata Kunci: : Anggur laut (Caulerpa sp), Takalar, Angka Lempeng Total (ALT)

\section{PENDAHULUAN}

Indonesia dikenal sebagai negara dengan luas wilayah laut lebih dari $70 \%$. Hasil laut umumnya adalah ikan, sedangkan alternatif hasil laut lainnya yang bisa diolah adalah rumput laut. Dalam dunia perdagangan, rumput laut merupakan salah satu komoditi yang cukup terkenal, meskipun tidak semua rumput laut memiliki nilai ekonomis. Rumput laut termasuk dalam golongan tanaman tingkat rendah dan anggota alga (tanaman yang memiliki klorofil atau zat hijau daun). Rumput laut diketahui kaya nutrisi esensial, seperti enzim, asam nukleat, asam amino, mineral, dan vitamin A, B, C, D, E, dan K (Abumie, 2007).

Alga yang hidup diperairan dangkal dan menempel pada karang yang mati ini dibagi kedalam 4 kelas besar, yaitu Rhodophyceac (alga merah), Phaeophyceae (alga cokelat), Cholorophyceae (alga hijau), dan Cyanophyceae (alga biru hijau) (Abumie 2007). Sebagian besar penanganan pasca panen rumput laut yang dilakukan oleh para nelayan cenderung masih tradisional. Beberapa jenis pengolahan yang dapat dilakukan sebagai bentuk dari usaha diversifikasi pengolahan rumput laut adalah dengan teknik pengeringan, pembuatan manisan, dan pembuatan acar rumput laut.

Anggur laut (Caulerpa sp) adalah golongan alga hijau, thallus (cabang) berbentuk lembarana, batangan dan bulatan, berstruktur lembut sampai keras dan siphonous. Rumpun terbentuk dari berbagai ragam percabangan, mulai dari sederhana sampai yang kompleks seperti yang terlihat pada tumbuhan tingkat tinggi, ada yang tampak seperti akar, batang dan daun. Seluruh bagian rumput laut Caulerpa sp terdiri atas assimilator dan ramuli yang membentuk bulatan-bulatan seperti buah anggur (Direktorat Jendral Perikanan Budidaya, 2009).

Habitat awalnya anggur laut (Caulerpa sp) berasal dari laut, akan tetapi anggur laut (Caulerpa sp) dapat dibudidayakan di kawasan pertambakan selama sirkulasi air pasang surut di 
kawasan pertambakan dapat terjaga dengan baik (Sunaryo, 2015).

Keberadaan anggur laut terbesar hampir di seluruh perairan indonesia. Oleh karena itu, masyarakat yang tinggal di wilayah pesisir dapat dengan mudah mengambil dan mengkonsumsi anggur lau (Caulerpa sp) tanpa dikelolah terlebih dahulu. Tetapi masyarakat belum mengetahui apakah anggur laut aman dikonsumsi secara langsung dan apakah tidak terdapat bakteri didalamnya. Bakteri adalah organisme bersel satu yang terlalu kecil untuk dilihat kecuali dengan bantuan mikroskop.

Beberapa cara dapat dilakukan untuk menentukan jumlah bakteri yang terdapat pada bahan pemeriksaan. Cara yang paling sering digunakan adalah cara perhitungan koloni pada lempeng pembiakan (plate count). Selain itu dapat diadakan penghitungan langsung secara mikroskopis. Ada beberapa cara yang dapat digunakan untuk menghitung jumlah mikroba salah satunya adalah cara menghitung secara langsung. Cara ini pada mulanya dilakukan dalam pemeriksaan bakteri yang terdapat dalam air susu,tetapi dapat digunakan untuk penelitian lain dengan cara yang terhitung baik bakteri hidup maupun mati. Sehingga dengan cara ini tidak diketahui berapa jumlah bakteri hidup, tetapi pengerjaannya lebih cepat (Irianto, 2006).

Berdasarkan latar belakang diatas maka peneliti berkeinginan melakukan penelitian tentang hitung jumlah bakteri pada anggur laut (Caulerpa $s p$ ) yang diperjualbelikan di sepanjang pantai Takalar.

\section{METODOLOGI PENELITIAN Alat dan Bahan}

Alat yang digunakan adalah Erlenmeyer, cawan petri, autoclave, timbangan, blender, pipet tetes, tabung reaksi, incubator, colony counter.

Bahan yang digunakan adalah anggur laut, media NA, aquades.

\section{Prosedur Penelitian Pembuatan media}

Media Nutrien Agar ditimbang sebanyak 20 g dalam $450 \mathrm{ml}$ Aguadest, kemudian dilarutkan dalam erlenmeyer, setalah itu dipanaskan di atas hotplate sampai mendidih. Setelah itu media dan cawan disterilkan di autoclave dengan suhu $121^{\circ} \mathrm{C}$ selama 15 menit. Setalah di sterilkan media di tuang kedalam cawan sebanyak $20 \mathrm{ml}$ setalah itu tunggu sampai padat.

\section{Pemeriksaan sampel}

Menimbang sampel sebanyak 25 gram. Kemudian sampel yang telah di timbang diblender sampai halus, setelah itu di masukkan ke plate sesuai kode sampel sebanyak 10 sampel dengan kode yang berbeda. Dari pengenceran tersebut dipipet $1 \mathrm{ml}$ dimasukkan kedalam tabung reaksi yang telah diisi oleh $\mathrm{NaCl}$ yang berisi sebanyak $9 \mathrm{ml}$ dengan cara memipet sampel $1 \mathrm{ml}$ kedalam masing-masing penggenceran. Dari sampel di pipet kedalam penggenceran $10^{-1}$ sebanyak $1 \mathrm{ml}$ perlakuan di lakukan sama sampai kepenggenceran $10^{-5}$. Dari masing-masing pengenceran dipipet $1 \mathrm{ml}$ dari tabung kemudian dimasukkan kedalam cawan petri steril yang dimana sudah berisi media, pada saat dimasukkan sampel plate di putar membentuk angka delapan. Dan diinkubasi selama 24 jam dengan suhu $37^{\circ} \mathrm{C}$.

\section{Pembacaan hasil}

Plate yang sudah di inkubasi di baca menggunakan coloni Counter, pembacaan bakteri dengan ciri-ciri koloni bulat sempurna. Setelah itu di musnahkan.

\section{HASIL DAN PEMBAHASAN}

Berdasarkan penelitian yang telah dilakukan pada tanggal 6-8 april $2019 \mathrm{di}$ Laboratorium Bakeriologi DIII Teknologi Laboratorium Medis Politeknik Kesehatan Muhammadiyah Makassar yaitu hitung angka kuman pada anggur laut (Caulerpa $s p$ ) di sepanjang pantai Takalar diperoleh hasil sebagai berikut: 
Tabel 1. Hasil Penelitian Hitung Jumlah Bakteri Pada Anggur Laut (Caulerpa yang diperjualbelikan di sepanjang pantai Takalar

\begin{tabular}{cccc}
\hline Sampel & $\begin{array}{c}\text { Jumlah } \\
\text { koloni }\end{array}$ & Pengenceran & $\begin{array}{c}\text { Coloni Forming } \\
\text { Unit (CFU) }\end{array}$ \\
\hline A & 133 & $10^{-1}$ & $1,3 \times 10^{3}$ \\
B & 62 & $10^{-1}$ & $6,2 \times 10^{2}$ \\
C & 33 & $10^{-1}$ & $3,3 \times 10^{2}$ \\
D & 155 & $10^{-1}$ & $1,5 \times 10^{3}$ \\
E & 50 & $10^{-1}$ & $5 \times 10^{2}$ \\
F & 50 & $10^{-1}$ & $5 \times 10^{2}$ \\
G & 48 & $10^{-1}$ & $4,8 \times 10^{2}$ \\
H & 46 & $10^{-1}$ & $4,6 \times 10^{2}$ \\
I & 39 & $10^{-1}$ & $3,9 \times 10^{2}$ \\
J & TBUD & TBUD & TBUD $<30$ \\
\hline
\end{tabular}

Dari tabel diatas diperoleh hasil dari perhitungan total koloni adalah pada sampel anggur laut (Caulerpa $s p$ ) A yaitu $1,3 \times 10^{-3} \mathrm{CFU}$, sampel anggur laut (Caulerpa sp) B yaitu $6,2 \times 10^{-2}$, sampel anggur laut (Caulerpa sp) C yaitu 3,3 x 103, sampel anggur laut (Caulerpa sp) D yaitu $1,5 \times 10^{-2}$, sampel anggur laut (Caulerpa sp) E yaitu $5 \times 10^{-2}$, sampel anggur laut (Caulerpa sp) F yaitu $5 \times 10^{-2}$, sampel anggur laut (Caulerpa $s p$ ) $\mathrm{G}$ yaitu $4,8 \times 10^{-2}$, sampel anggur laut (Caulerpa $s p$ ) $\mathrm{H}$ yaitu $4,6 \times 10^{-2}$, sampel anggur laut (Caulerpa $s p$ ) I yaitu 3,9 x 10-2, sampel anggur laut (Caulerpa $s p$ ) $\mathrm{J}$ yaitu TBUD < 30. Berdasarkan hasil penelitian dari 10 sampel anggur laut (Caulerpa sp) yang dilakukan di Laboratorium Bakeriologi DIII Teknologi Laboratorium Medis Politeknik Kesehatan Muhammadiyah Makassar didapatkan angka kuman atau total koloni dengan mengalikan jumlah koloni dengan faktor pengenceran.

Jarak pengambilan sampel A dari jarak pantai yaitu 10 meter, sampel B dari jarak pantai yaitu 15 meter, sampel C dari jarak pantai yaitu 20 meter, sampel D dari jarak pantai yaitu 15 meter, sampel $\mathrm{C}$ sekitar 10 meter dari jarak pantai, sampel E dari jarak pantai yaitu 10 meter, sampel $F$ dari jarak pantai 15 meter, sampel G dari jarak pantai 12 meter, sampel H dari jarak pantai 10 meter, sampel I dari jarak pantai 25 meter, sampel J dari jarak pantai $30 \mathrm{M}$.

Jenis penelitian yang digunakan pada penelitian ini bersifat observasi laboratorik yang bertujuan untuk mengetahui jumlah bakteri pada anggur laut. Proses pemeriksaan terhadap sampel penelitian diawali dengan pengumpulan 10 sampel anggur laut disepanjang pantai Takalar. Pemeriksaan 10 sampel ini dimulai dengan penanaman pada media NA (Natrium Agar), kemudian diinkubasi selama 48 jam pada suhu $37^{\circ} \mathrm{C}$. Setelah diinkubasi selama selama 48 jam, terdapat pertumbuhan koloni yang akan dihitung. Satuan perhitungan jumlah mikroba dikenal dengan istilah Colony Forming Unit (CFU) untuk perhitungan jumlah mikroba.

Setelah melakukan pengamatan langsung pada 10 sampel anggur laut yang diisolasi pada media NA (Nutrien Agar) terdapat 9 sampel yang memenuhi syarat untuk dihitung yaitu memiliki koloni 30300 dengan nomor sampel 1, 2, 3, 4, 5, 6, 7,8 , dan 9. Sedangkan pada sampel nomor 10 tidak memenuhi syarat untuk dihitung karena jumlah kolon yang tumbuh yaitu kurang dari 30. 
Perhitungan bakteri pada penelitian ini Angka lempeng tota Hitung cawan merupakan metode yang sensitive untuk menentukan jumlah sel mikroba. Prinsip metode hitung adalah jika sel mikroba yang masih hidup ditumbuhkan pada media agar, maka sel mikroba itu akan berkembang biak membentuk koloni yang dapat dilihat dan dihitung langsung, dan disebut dengan 'Colony Forming Unit' = CFU sehingga jika pertumbuhan mikroba terlalu padat maka harus dilakukan pengenceran terlebih dahulu (Ibrahim, 2016).

CFU (Colony Forming Unit) untuk perhitungan bakteri, perhitungan bakteri ini digunakan untuk mengetahui jumlah bakteri pada anggur laut (Caulerpa sp). Analisis ini menggunakan standar yang disebut standar plate count yang menunjukkan mengenai cara menghitung koloni pada cawan serta cara memilih data yang ada untuk menghitung jumlah koloni pada anggur laut. Koloni dihitung untuk menentukan banyaknya mikroba pada anggur laut dan bertujuan untuk mengetahui sampai berapa jauh anggur laut itu tercemar oleh bakteri. Dengan mengetahui jumlah bakteri yang ada pada anggur laut maka dapat diketahui bahwa apakah anggur laut masih layak untuk di konsumsi atau tidak.

Berdasarkan standar SNI (2009), batas maksimum jumlah mikroba yang diperbolehkan ada dalam makanan adalah $1 \times 10^{-4}$ koloni /g. Koloni yang tumbuh menunjukkan bahwa adanya mikroba yang tumbuh dari penyebaran bakteri baik dari udara dan beberapa faktor seperti makanan yang tidak dimasak dengan matang. Makanan yang tercemar oleh bakteri dan dikonsumsi oleh manusia dapat menyebabkan gangguan kesehatan. Adapun gangguan kesehatan yang di sebabkan apabila anggur laut (Caulerpa $s p$ ) yang terkontaminasi bakteri dikonsumsi antara lain diare, mual, penyakit gastrointestinal, dan bahkan meningitis.

\section{KESIMPULAN}

Berdasarkan perhitungan jumlah bakteri pada anggur laut (Caulerpa $s p$ ) yang diperjual belikan di sepanjang Pantai Takalar diperoleh jumlah bakteri paling sedikit pada sampel C, yaitu $3,3 \times 10^{2} \mathrm{CFU}$ dan paling banyak pada sampel D yaitu $1,5 \times 10^{3} \mathrm{CFU}$ sehingga anggur laut (Caulerpa sp) yang diperjualbelikan di sepanjang pantai Takalar masih layak untuk dikonsumsi.

\section{SARAN}

Saran kepada calon peneliti selanjutnya sebaiknya bagi peneliti selanjutnya disarankan untuk melakukan pemeriksaan hitung jumlah bakteri pada sampel anggur laut (Caulerpa $s p$ ) dan metode yang berbeda..

\section{DAFTAR PUSTAKA}

Abumie. 2007. Rumput Laut Kaya Serat Penuh Manfaat [Online]. From: http://www.abumie.wordpress.com. [Acessed on 26 April 2015].

Atmadja, W.S., A. Kadi; Sulistijo dan Rachmaniar. 1996. Pengenalan Jenisjenis Rumput Laut indonesia. Puslitbang Oseanologi-LIPI. Jakarta

Badan Standar Nasional. 2009. (SNI 7388:2009). Batas Maksimum Cemaran Mikroba Dalam Pangan. Badan Standarisasi Nasional. Jakarta.

Direktorat Jendral Perikanan Budidaya. 2009. Profil Rumput Laut Di Indonesia. Direktorat Pembudidayaan Departemen Kelautan dan Perikanan.

Direktorat Jendral Perikanan Budidaya. 2005. Profil Rumput Laut Indonesia. DKP RI, Ditjenkanbud. Jakarta. Hal 11

Depertemen kelautan dan perikanan. 2009. Profil Rumput Laut Indonesia. Jakarta : Depertemen Kelautan dan Perikanan.

Dwihandita. 2009. Perubahan kandungan Antioksidan Anggur Laut (Caulerpa racemosa) Akibat Pengolahan. Skripsi. Departemen Teknologi Hasil Perairan. Bogor : Institusi Pertanian Bogor.

FAO (Food and Agricultural Organization). 2007. Cholorphyta- 
gree

http://fao.org/dorcep/fao/009/w71gle /w71gle04.pdf._Diakses tanggal 20 maret 2019.

Irianto, K. 2006. Mikrobiologi Menguak Dunia Mkroorganisme. Jilid 1. Bandung : Yrama widya.

Sherly, R., \& Asnani. 2016. Potensi Anggur Laut Kelompok Caulerpa sp Sebagai Kandidat Sumber Pangan Fungsional Indonesia. Jurnal Kelautan vol XLI, Nomor 4 hal 50-62.
Suhartini, S. 2003. Penapisan Awal Caulerpa racemosa, Sesuvium portalcastrum, Xylocarpus granatum dan Ulva lactuca sebagai Antimikroba. Skripsi. Bogor. Program Studi dan Teknologi Hasil Perikanan Fakultas Perikanan dan Ilmu Kelautan. Institude Pertanian Bogor.

Palczar, M.J \& E.C.S Chan, 1986, penerjemah, Ratna Siri Hadioetomo dkk. Dasar-dasar mikrobiologi I, Universitas Indonesia press, Jakarta. 